\title{
Influence of current or former smoking on asthma management and control
}

\author{
Louis-Philippe Boulet MD FCCP FRCPC ${ }^{1}$, J Mark FitzGerald FRCPC ${ }^{2}$, R Andrew Mclvor FRCPC ${ }^{3}$, \\ Sabrina Zimmerman ${ }^{4}$, Kenneth R Chapman FRCPC ${ }^{5}$
}

L-P Boulet, JM FitzGerald, RA McIvor, S Zimmerman, KR Chapman. Influence of current or former smoking on asthma management and control. Can Respir J 2008;15(5):275-279.

BACKGROUND: In patients with asthma, smoking has been associated with accelerated decline in pulmonary function, poor disease control and reduced responsiveness to corticosteroids.

OBJECTIVE: To assess the influence of current and former smoking on self-reported asthma control and health care use in a large population of asthma patients.

METHODS: The present analysis was conducted following a telephone survey of adult Canadians aged 18 to 54 years who had physician-diagnosed asthma and a smoking history of less than 20 pack-years.

RESULTS: Of 893 patients, 268 were former smokers and 108 were current smokers. Daytime and nighttime symptoms, absenteeism from work or school, emergency care use for asthma in the past year, and use of a short-acting bronchodilator without controller medication were reported more frequently by current smokers than nonsmokers and former smokers. Former smokers were not significantly different from nonsmokers with respect to most asthma outcomes. CONCLUSIONS: Current smokers with asthma show evidence of poorer asthma control and greater acute care needs than lifelong nonsmokers or former smokers. These observations stress the importance of smoking cessation to help achieve asthma control.

\section{L'influence du tabagisme courant et passé sur la prise en charge et le contrôle de l'asthme}

\begin{abstract}
HISTORIQUE : Chez les patients asthmatiques, le tabagisme s'associe à l'accélération du déclin de la fonction pulmonaire, au mauvais contrôle de la maladie et à une moins bonne réponse aux corticoïdes.

OBJECTIF : Évaluer l'influence du tabagisme courant et passé sur le contrôle de l'asthme et l'utilisation des soins de santé autodéclarés par une large population de patients asthmatiques.

MÉTHODOLOGIE : La présente analyse a été menée après une enquête téléphonique auprès d'adultes canadiens de 18 à 54 ans atteints d'asthme diagnostiqué par un médecin et des antécédents de tabagisme de moins de 20 paquets par année.

RÉSULTATS : Sur les 893 patients, 268 étaient d'anciens fumeurs et 108, des fumeurs. Les symptômes diurnes et nocturnes, l'absentéisme au travail ou à l'école, les consultations à l'urgence à cause de l'asthme au cours de l'année précédente et l'utilisation d'un bronchodilatateur à action brève sans médicaments de contrôle étaient plus fréquents chez les fumeurs que chez les non-fumeurs ou les anciens fumeurs. Les anciens fumeurs ne différaient pas de manière significative des non-fumeurs à l'égard de la plupart des issues de l'asthme.

CONCLUSIONS : Les fumeurs asthmatiques démontrent un moins bon contrôle de l'asthme et de plus grands besoins de soins aigus que les personnes qui n'ont jamais fumé ou que les anciens fumeurs. Ces observations soulignent l'importance d'arrêter de fumer pour contrôler l'asthme.
\end{abstract}

Key Words: Asthma; Asthma control; Asthma management; Smoking

substantial number of patients with asthma currently
smoke, the prevalence of which is comparable with the
prevalence of smokers in the general population (1,2). Smoking
has been associated with poor asthma control, increased health
care use and asthma severity, increased sputum neutrophils,
increased lung hyperinflation, increased prevalence of radiologi-
cal abnormalities and accelerated decline in lung function (3-7).
Furthermore, asthma medications such as inhaled corticos-
teroids (ICSs) have been found to be less effective in smokers
(8,9). The need for smoking cessation is often emphasized in
asthma management guidelines, but the effect of smoking cessa-
tion on asthma control remains poorly documented (10). The few studies available are on small groups of patients without assessment of asthma control as suggested in current guidelines.

The Reality of Asthma Control (TRAC) study (11), a large pan-Canadian survey, was conducted to provide insights into current asthma control, perceptions of such control, and various aspects of asthma care. In the context of this study, we herein report the results of an analysis of asthma control and characteristics in smokers and former smokers in comparison with lifelong nonsmokers. Our main goal was to compare selfreported asthma control and health care use among the three groups studied to assess the influence of current or past smoking on these asthma outcomes.

${ }^{1}$ Unité de recherche en pneumologie, Centre de recherche de l'Hôpital Laval, Institut Universitaire de Cardiologie et de Pneumologie de l'Université Laval, Quebec City, Quebec; ${ }^{2}$ Centre for Clinical Epidemiology and Evaluation, University of British Columbia, Vancouver, British Columbia; ${ }^{3}$ Division of Respirology, Firestone Institute for Respiratory Health, St Joseph's Healthcare, Hamilton; ${ }^{4}$ AstraZeneca Canada Inc, Mississauga;

${ }^{5}$ Asthma and Airway Centre, University Health Network, Toronto Western Hospital, University of Toronto, Toronto, Ontario

Correspondence: Dr Louis-Philippe Boulet, Hôpital Laval, 2725 Chemin Sainte-Foy, Quebec City, Quebec G1V 4G5. Telephone 418-656-4747, fax 418-656-4762, e-mail lpboulet@med.ulaval.ca 
TABLE 1

Typical frequency of daytime symptoms

\begin{tabular}{|c|c|c|c|c|c|c|c|c|c|c|c|c|c|c|c|c|}
\hline & & & & & \multicolumn{6}{|c|}{ Sex } & \multicolumn{6}{|c|}{ Smoking history, pack-years } \\
\hline & \multicolumn{4}{|c|}{ Total } & \multicolumn{2}{|c|}{ NS } & \multicolumn{2}{|c|}{ FS } & \multicolumn{2}{|c|}{ CS } & \multicolumn{3}{|c|}{ FS } & \multicolumn{3}{|c|}{ CS } \\
\hline & Total & NS & FS & cs & M & $\mathbf{F}$ & $\mathbf{M}$ & $\mathbf{F}$ & $\mathbf{M}$ & $\mathbf{F}$ & $1-4$ & $5-9$ & $10-19$ & $1-4$ & $5-9$ & $10-19$ \\
\hline \multicolumn{17}{|c|}{ Frequency of symptoms, $\%$} \\
\hline$<1$ day per week & 39 & 42 & 40 & 32 & 43 & 40 & 45 & 39 & 38 & 28 & 41 & 35 & 43 & 37 & 19 & 33 \\
\hline $1-3$ days per week & 36 & 36 & 38 & 35 & 33 & 38 & 38 & 38 & 24 & 39 & 40 & 43 & 33 & 38 & 37 & 30 \\
\hline $\begin{array}{l}\text { Unknown or } \\
\text { not applicable }\end{array}$ & 5 & 7 & 3 & 4 & 9 & 5 & 3 & 2 & 5 & 4 & 2 & 3 & 3 & 6 & 2 & 5 \\
\hline
\end{tabular}

The sum of percentages may not be exactly $100 \%$ because the numbers have been rounded for each subgroup. CS Current smokers; F Female; FS Former smokers; M Male; NS Nonsmokers

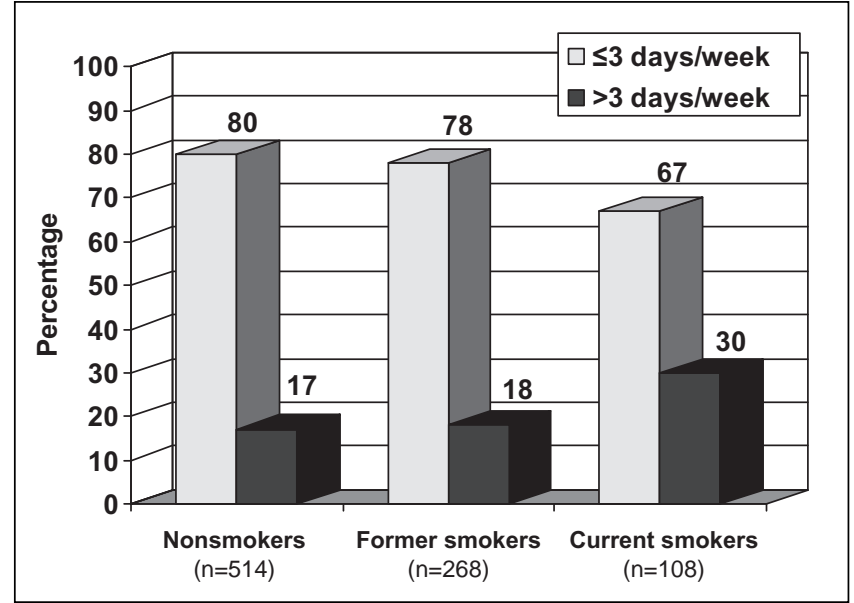

Figure 1) Proportion of subjects with daytime symptoms of asthma. Current smokers were less likely than former smokers or nonsmokers to fulfill the asthma control criteria to have diurnal asthma symptoms less than four days per week

\section{METHODS}

Between April and August 2004, trained survey staff members from an independent research company (Environics Research Group, Ontario) telephoned 26,210 Canadian households. The national sample frame was provided by a company that obtains consumer information. At least five telephone calls were made to a household before it was classified as "no answer'. When a household had more than one individual with asthma, the subject with the most recent birthday was chosen for the survey. More detailed information on the survey methods has been previously published (11).

The analysis included men or women 18 to 54 years of age with a physician's diagnosis of asthma made at least six months previously. Respondents who had a smoking history of 20 or more pack-years, as well as those with physician-diagnosed chronic obstructive pulmonary disease (COPD), were excluded from the survey. Categories were based on respondents' selfreported smoking history (never smoked, had quit smoking or were current smokers), the duration of time they smoked and the number of cigarettes typically smoked per day.

These subgroups were further subdivided by sex, asthma control (controlled or uncontrolled) and pack-year history of smoking. Asthma control status was established based on answers to specific survey questions using criteria of control outlined in the Canadian asthma consensus guidelines (12). These parameters include daytime symptoms less than four days per week, nighttime symptoms less than one night per week, normal physical activity, no absenteeism from work or school, use of rescue bronchodilator fewer than four times a day per week, and rare and mild exacerbations. Patients who failed two or more of the survey's six control parameters were classified as having uncontrolled asthma. Asthma worsening was defined as a time when symptoms increased, and asthma exacerbation as an episode that required acute care (unscheduled physician visit, emergency department visit or overnight hospitalization). Asthma severity and compliance to therapy were estimated by the patient.

The main analyses were performed on asthma control parameters while for the other elements, secondary analyses were considered exploratory and hypothesis generating.

\section{RESULTS}

Of 6128 households contacted by telephone, 45 declined an interview and less than $1 \%(n=29)$ stopped mid-interview. In addition, $48 \%$ of 6537 numbers dialed resulted in 'no answer, line busy or respondents not available', despite a minimum of five call-backs in an attempt to reach these potential respondents. Complete interview results were available for 514 nonsmokers, 268 former smokers and 108 current smokers with asthma.

\section{Asthma control}

Globally, the proportion of patients with controlled asthma tended to be higher among nonsmokers and former smokers than among current smokers, although these differences were not statistically significant (48\%, 49\% and 39\%, respectively). However, nonsmokers and former smokers were significantly less likely than current smokers to have daytime symptoms of asthma four or more days per week (17\% of nonsmokers, $18 \%$ of former smokers and $30 \%$ of current smokers; $\mathrm{P}<0.05$ ) (Table 1, Figures 1 and 2). Current smokers with a smoking history of one to four pack-years were less likely to have daytime symptoms four or more days per week than those with five to 19 pack-years (Figure 2). Nonsmokers and former smokers were more likely than current smokers to report that their asthma symptoms never keep them from going to school or work, or from doing their usual activities at home (70\%, 76\% and $61 \%$, respectively; $\mathrm{P}<0.01)$. 


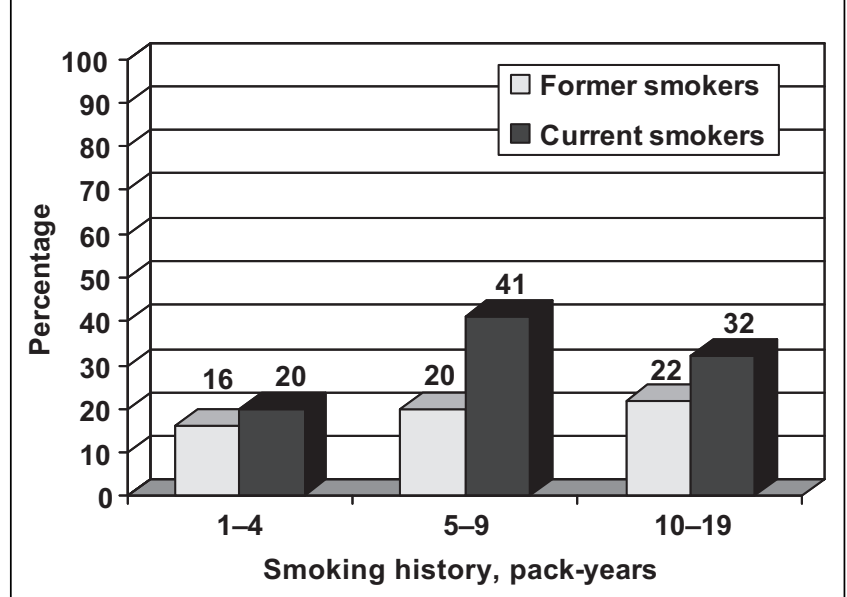

Figure 2) Proportion of subjects with uncontrolled asthma for more than three days per week. Current smokers with a smoking history of one to four pack-years were less likely to have daytime symptoms four or more days per week than those with five to 19 pack-years

There were no significant differences between nonsmokers, former smokers and current smokers with regard to the frequency of nighttime awakening because of coughing, wheezing, chest tightness or shortness of breath (47\%, 53\% and 46\%, respectively).

\section{Assessment of asthma control by patients}

All patient groups overestimated their degree of asthma control. Among nonsmokers, former smokers and current smokers, $98 \%, 98 \%$ and $94 \%$, respectively, regarded their asthma as well controlled (Figure 3). The actual proportions of those with well-controlled disease according to current asthma guidelines were $48 \%$ of nonsmokers, $49 \%$ of former smokers and 39\% of current smokers.

\section{Assessment of asthma severity}

When nonsmokers, former smokers and current smokers were asked to describe the severity of their asthma, a majority reported having mild asthma $(60 \%, 60 \%$ and $52 \%$, respectively) followed by moderate (33\%, $37 \%$ and $41 \%$, respectively) and severe (8\%, $4 \%$ and 5\%, respectively) asthma.

\section{Medication use}

Approximately $90 \%$ of nonsmokers, former smokers and current smokers reported using at least one prescription medication for their asthma. Current smokers were less likely than former smokers and nonsmokers to report taking an ICS in association with a long-acting beta 2 -agonist (LABA) $(12 \%$, $20 \%$ and $24 \%$, respectively: $12 \%$ versus $20 \%, \mathrm{P}<0.05 ; 12 \%$ versus $24 \%, \mathrm{P}<0.01)$. There were no statistically significant differences among the three groups with respect to the proportion using ICSs (42\%, 44\% and 40\%, respectively).

\section{Knowledge}

Awareness of the way reliever medications work (as assessed by specific questions on their mode of action) tended to be greater among women who formerly smoked than among men who formerly smoked ( $86 \%$ versus $77 \%$, respectively); among those aware of how reliever medications worked, there were more current smokers who were not controlled than among those

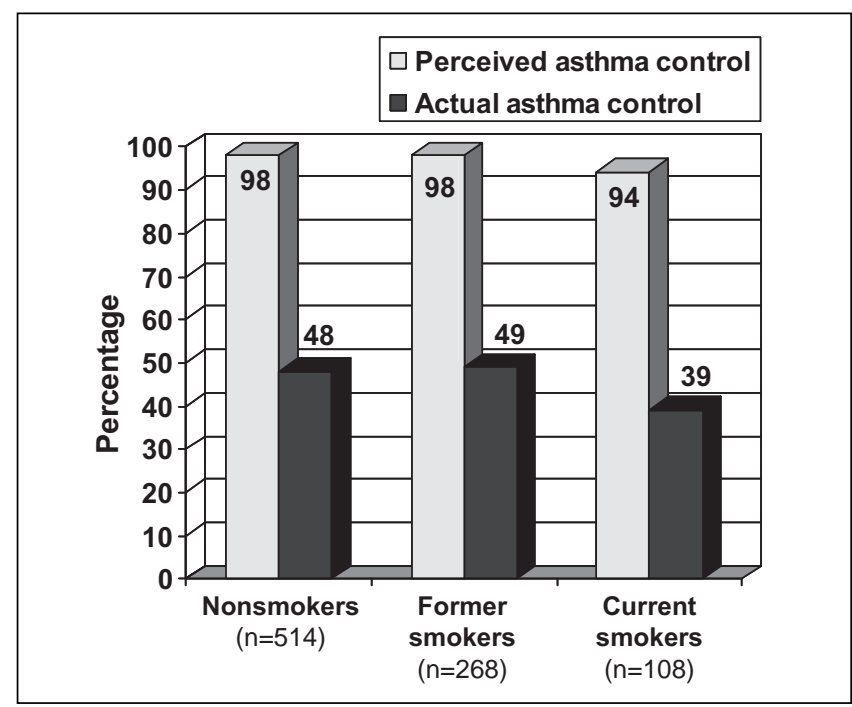

Figure 3) Perceived versus actual control of asthma. The degree of asthma control was overestimated in all groups, but particularly in smokers

who were ( $84 \%$ versus $68 \%$, respectively), and it was significantly greater in current smokers with a smoking history of five to 19 pack-years than those who smoked less ( $85 \%$ versus $65 \%$, respectively).

When subjects who had heard of controller medications (373 nonsmokers, 215 former smokers and 71 current smokers) were asked with what frequency controller medications should be used, nonsmokers were slightly more likely to be aware that these medications should be used regularly ( $74 \%$, compared with $68 \%$ of both former and current smokers). However, a minority believed incorrectly that controller medications should be used as needed. Among current smokers, awareness that controller medications should be used regularly tended to be greater among women than among men (73\% and 54\%, respectively). Among nonsmokers, awareness was greater among those who were not controlled than among those who were controlled ( $78 \%$ and $69 \%$, respectively). A similar pattern emerged among current smokers $(74 \%$ did not have controlled asthma and 54\% had controlled asthma). However, among former smokers, a higher level of awareness was found among those who were not controlled (75\%, compared with $62 \%$ of asthma patients who were not controlled).

\section{Beliefs}

When questioned on their willingness to be involved in their asthma care, nonsmokers and former smokers were more likely than current smokers to say they preferred to take more responsibility or control than they were currently given, if guided by an action plan indicating how they should manage their medication during exacerbations and improvements in their condition $(71 \%, 68 \%$ and $59 \%$, respectively). Current smokers were more likely than nonsmokers and former smokers to prefer that their physician be responsible for making changes to their medication (38\%, 28\% and 29\%, respectively).

\section{Use of an action plan}

Among nonsmokers, former smokers and current smokers, only one in 10 patients reported having a written plan $(10 \%, 14 \%$ 
and $12 \%$, respectively). Very few reported having both verbal and written plans ( $6 \%, 5 \%$ and $3 \%$, respectively). Women were more likely than men to report having a plan of some sort among both former smokers (60\% versus $48 \%$, respectively) and current smokers (53\% versus 33\%, respectively). Patients with asthma who were not controlled were more likely than those who were controlled to report having an asthma treatment plan, whether they be nonsmokers (63\% versus 52\%, respectively), former smokers ( $60 \%$ versus $50 \%$, respectively) or current smokers (56\% versus $32 \%$, respectively). Nonsmokers and former smokers were less likely than current smokers to say they did not use their plan $(11 \%, 16 \%$ and $21 \%$, respectively). Among former smokers, men tended to report more regular use of their plan than women (63\% versus $48 \%$, respectively).

Interestingly, although the specific type of instructions was quite variable across groups in terms of the actual content, current smokers were more likely than nonsmokers and former smokers to report that their asthma treatment plan included instructions on when to go to the emergency room $(32 \%, 16 \%$ and $18 \%$, respectively).

\section{Adherence to medication}

Reported adherence was greater among all controlled asthma patients, whether they were nonsmokers ( $87 \%$, compared with $56 \%$ of uncontrolled nonsmokers), former smokers (77\%, compared with $59 \%$ of uncontrolled former smokers) or current smokers $(95 \%$, compared with $44 \%$ of uncontrolled current smokers). Among former smokers, reported adherence was greater among women than among men (73\% versus 59\%, respectively). Among current smokers, adherence was greater for those with a smoking history of one to four pack-years than among heavier smokers ( $80 \%$ versus $57 \%$, respectively).

Current smokers were more likely than other asthma patients interviewed to be on short-acting beta 2 -agonists (SABAs) alone, and were less likely to be on a combination of ICS and LABA medications. Further analysis among current smokers indicated that women were more likely than men to be using an ICS with a SABA (45\% versus 22\%). Among current smokers, those who were not controlled were more likely than those who were controlled to use ICS plus SABA ( $47 \%$ versus $22 \%$, respectively). Among former smokers, those with a smoking history of 10 to 19 pack-years were more likely (than lighter smokers) to be classified as controller plus SABA users (36\% versus $21 \%$, respectively).

\section{Perception of treatment}

Nonsmokers and former smokers were slightly more likely than current smokers to be concerned about their asthma treatment (80\%, $76 \%$ and $68 \%$, respectively). Among current smokers, women tended to express greater concern than men about the side effects of asthma medications (37\% versus $24 \%$, respectively). Seventy-six per cent of nonsmokers, $73 \%$ of former smokers and $70 \%$ of current smokers reported that they were concerned about the use of ICSs. Among current smokers, concerns about ICS use were greater among women than men ( $42 \%$ versus $24 \%$, respectively).

\section{Health care use}

Approximately one-half of nonsmokers, former smokers and current smokers reported having made an unscheduled visit to their doctor or a walk-in clinic to receive treatment for their asthma in the past year (43\%, 49\% and 47\%, respectively).
Routine use of walk-in clinics was greater among those who were not controlled than among those who were controlled, whether they were nonsmokers (26\% versus 12\%, respectively), former smokers (28\% versus $10 \%$, respectively) or current smokers ( $41 \%$ versus $23 \%$, respectively).

Nonsmokers were less likely than former smokers or current smokers to report having received care in the emergency department for their asthma in the past year $(14 \%, 22 \%$ and $28 \%$, respectively). However, among nonsmokers, emergency department use was greater among women than among men ( $19 \%$ versus $8 \%$, respectively).

\section{DISCUSSION}

The present study shows that patients with asthma who smoke have worse control of their asthma than patients with asthma who have stopped smoking or who have never smoked. Overall, the proportion of patients currently smoking (108 of 893 subjects [12\%]) was lower than that of the general population (approximately 25\%) (2). This difference may have been due to our exclusion of subjects who had a smoking history of 20 pack-years or more, because the prevalence of smoking is relatively similar in asthmatic and nonasthmatic populations. We nevertheless restricted enrolment of patients to those aged 18 to 54 years and patients with less than 20 pack-years of smoking to avoid diagnostic problems, particularly in elderly patients whose COPD may be confounded with asthma in smokers. A further potential selection bias in the study might be a greater willingness of those having less controlled asthma to respond to a telephone survey. However, we would not expect this selection bias, if present, to alter the relationship between smoking status and asthma control.

Our evaluation of asthma control in former smokers is novel. Indeed, there are minimal data on asthma outcomes following smoking cessation. Stein et al (13) have reported a reduction in symptom severity as reduction in daily smoking increased. This study was, however, not performed specifically among asthma patients.

Tønnesen et al (10) also reported that smoking cessation resulted in a marked improvement in daytime asthma symptoms, nighttime waking, bronchial hyperresponsiveness, medication use and lung function, whereas smoking reduction only had a small effect on asthma control. Our analysis extends these data in showing that for most control criteria and health care use, former smokers were similar to lifelong nonsmokers after smoking cessation. The time course of improvement following smoking cessation is unclear.

It has been suggested previously that asthma control is more difficult to achieve in smokers than nonsmokers $(3,4,7)$. We have also found consistent trends toward worse asthma control among smokers, with increased use of reliever medication. Such 'poor control' may reflect the effects of underlying conditions such as chronic bronchitis, but it is difficult to distinguish the effects of smoking from its consequences on asthma. However, these patients were unlikely to have symptoms related to underlying COPD because they smoked less than 20 packyears and asthma control was similar to lifelong nonsmokers after smoking cessation. Comorbidities may also have influenced the results in smokers, and this should be further examined. Emergency department visits were less frequent in nonsmokers and more frequent in uncontrolled patients, for all groups. Patients in all three groups overestimated the control of their disease. 
Reported use of ICS was similar (approximately 40\%) in the three groups, but smokers were using less combination (ICS and LABA) therapy. It has, however, been reported that smokers have a reduced response to ICS (8). These patients may therefore have had suboptimal treatment. Further research should investigate the effects of combined ICS and LABA, as well as the effect of anticholinergic agents, on respiratory status of asthmatic smokers. Because smokers were less likely to be on combined ICS and LABA treatment, this may explain, in part, their poorer control. Smokers were more likely to be on SABA alone, medication that was regularly used in many subjects contrary to guideline recommendations. A minority of patients in all three groups had an action plan for the management of asthma exacerbations, confirming this care gap in asthma management. For those with a plan, smokers were less likely to use it regularly. The fact that uncontrolled patients more often had an action plan may be because they had more severe or more difficult to control asthma. Furthermore, smokers tended to be less concerned about the side effects of asthma medications.

Many asthma patients who smoke are not aware of, or underestimate, the consequences of smoking on their condition (14). In this regard, Silverman et al (15) reported that among asthma patients who smoke presenting to an emergency department for acute asthma, 50\% admitted that smoking worsened their asthma symptoms, but only $4 \%$ stated that smoking was contributing to their current exacerbation. Efforts should therefore be devoted to specifically target this group of asthma patients with regard to preventive and educational initiatives (16).

Among current smokers, awareness that controller medications should be used regularly was greater for women than for men. In addition, woman were more likely than men to report having a plan for managing their asthma, although men mentioned that they were using them more regularly. This is in keeping with one of our previous reports showing that women more frequently use ICSs and have a better knowledge base than men with regard to asthma and its treatment, while men report greater need for urgent care (17).

\section{REFERENCES}

1. Canadian Institute for Health Information, Canadian Lung Association, Health Canada, Statistics Canada. Respiratory disease in Canada. Ottawa: Health Canada, 2001. <http://www.phac-aspc. gc.ca/publicat/rdc-mrc01/index.html> (Version current at June 25, 2008).

2. Lemiere C, Boulet LP. Cigarette smoking and asthma: A dangerous mix. Can Respir J 2005;12:79-80.

3. Althuis MD, Sexton M, Prybylski D. Cigarette smoking and asthma symptom severity among adult asthmatics. J Asthma 1999;36:257-64.

4. Ulrik CS, Lange P. Cigarette smoking and asthma. Monaldi Arch Chest Dis 2001;56:349-53.

5. Siroux V, Pin I, Oryszczyn MP, Le Moual N, Kauffmann F. Relationships of active smoking to asthma and asthma severity in the EGEA study. Epidemiological study on the Genetics and Environment of Asthma. Eur Respir J 2000;15:470-7.

6. Lange P, Parner J, Vestbo J, Schnohr P, Jensen G. A 15-year follow-up study of ventilatory function in adults with asthma. N Engl J Med 1998;339:1194-200.

7. Boulet LP, Lemière C, Archambault F, Carrier G, Descary MC, Deschesnes F. Smoking and asthma: Clinical and radiologic features, lung function, and airway inflammation. Chest 2006;129:661-8.

8. Chalmers GW, Macleod KJ, Little SA, Thomson LJ, McSharry CP, Thomson NC. Influence of cigarette smoking on inhaled corticosteroid treatment in mild asthma. Thorax 2002;57:226-30.

\section{CONCLUSION}

The present study suggests that the control of asthma is poor in smokers and suggests that smoking cessation is associated with improved disease control, achieving a level similar to lifelong nonsmokers. These results strongly support the importance of engaging asthma patients in the often difficult task of smoking cessation. These results also stress the need for further studies to evaluate the time course of improvement after smoking cessation, and to assess changes in inflammatory markers during this time frame.

POTENTIAL FINANCIAL CONFLICTS OF INTEREST: Consultancies: L-P Boulet (Altana, AstraZeneca, GlaxoSmithKline, Merck Frosst, Novartis), JM FitzGerald (AstraZeneca, GlaxoSmithKline), RA McIvor (Altana, AstraZeneca, GlaxoSmithKline), KR Chapman (Altana, AstraZeneca, Biovail, Boehringer-Ingelheim, Genpharm, GlaxoSmithKline, Hoffman LaRoche, Merck Frosst, Novartis, Pfizer, Schering-Plough, Telacris).

Honoraria: L-P Boulet (3M, Altana, AstraZeneca, GlaxoSmithKline, Merck Frosst, Novartis), JM FitzGerald (AstraZeneca, GlaxoSmithKline), RA McIvor (Altana, AstraZeneca, GlaxoSmithKline), KR Chapman (3M, Altana, AstraZeneca, Boehringer-Ingelheim, GlaxoSmithKline, Merck Frosst, Novartis, Pfizer, Telacris).

Grants received: L-P Boulet (3M, AllerGen, Altana, Asthmax, AstraZeneca, Boehringer-Ingelheim, Canadian Institutes of Health Research, Dynavax, Fonds de recherche en Santé du Québec, Genentech, GlaxoSmithKline, Institut de Recherche en Santé et Sécurité au Travail du Québec, IVAX, Merck Frosst, National Institute for Occupational Safety and Health [Centers for Disease Control and Prevention], Novartis, Pfizer, Roche, Québec Asthma and Chronic Obstructive Pulmonary Disease Network [Towards Excellence in Asthma Management], Schering, Topigen), JM FitzGerald, KR Chapman (3M, Altana, Amgen, AstraZeneca, Bayer, Boehringer-Ingelheim, GlaxoSmithKline, Hoffman-LaRoche, Merck Frosst, Novartis, Telacris, Theratechnologies). S Zimmerman is employed at AstraZeneca and has no conflict of interest.

FUNDING: This study was supported by AstraZeneca Canada Ltd.

9. Livingston E, Thomson NC, Chalmers GW. Impact of smoking on asthma therapy: A critical review of clinical evidence. Drugs 2005;65:1521-36.

10. Tønnesen P, Pisinger C, Hvidberg S, et al. Effects of smoking cessation and reduction in asthmatics. Nicotine Tob Res 2005;7:139-48.

11. FitzGerald JM, Boulet LP, McIvor RA, Zimmerman S, Chapman KR. Asthma control in Canada remains suboptimal: The Reality of Asthma Control (TRAC) study. Can Respir J 2006;13:253-9.

12. Lemière C, Bai T, Balter M, et al. Adult Asthma Consensus Guidelines Update 2003. Can Respir J 2004;11(Suppl A):9A-18A.

13. Stein MD, Weinstock MC, Herman DS, Anderson BJ. Respiratory symptom relief related to reduction in cigarette use. J Gen Intern Med 2005;20:889-94.

14. Wakefield M, Ruffin R, Campbell D, Roberts L, Wilson D. Smoking-related beliefs and behaviour among adults with asthma in a representative population sample. Aust N Z J Med 1995;25:12-7.

15. Silverman RA, Boudreaux ED, Woodruff PG, Clark S, Camargo CA Jr. Cigarette smoking among asthmatic adults presenting to 64 emergency departments. Chest 2003;123:1472-9.

16. Loddenkemper R, Sybrecht GW. Health care costs of smoking. Eur Respir J 2000;16:377-8.

17. Day A, Ernst P, Glick L, Zimmerman S, Chapman KR. Women and asthma: Lessons from a gender analysis of the asthma in Canada survey. J Asthma 2006:43:169-73. 


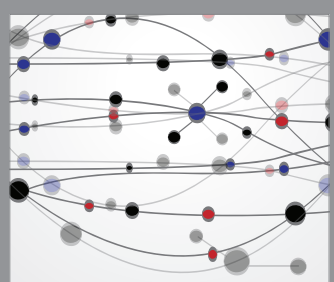

The Scientific World Journal
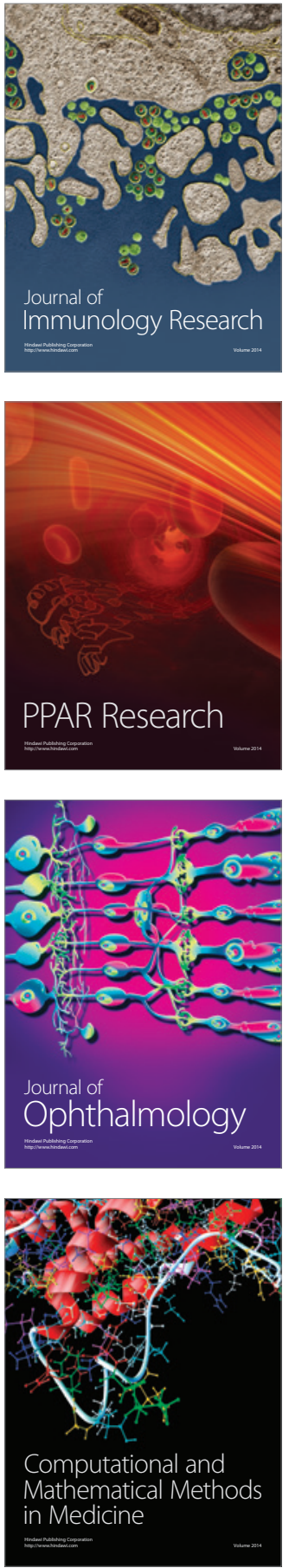

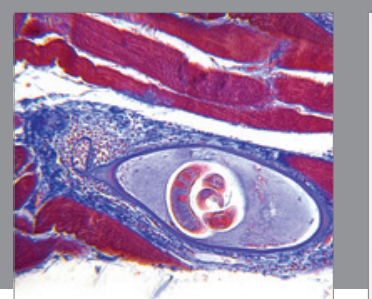

Gastroenterology Research and Practice

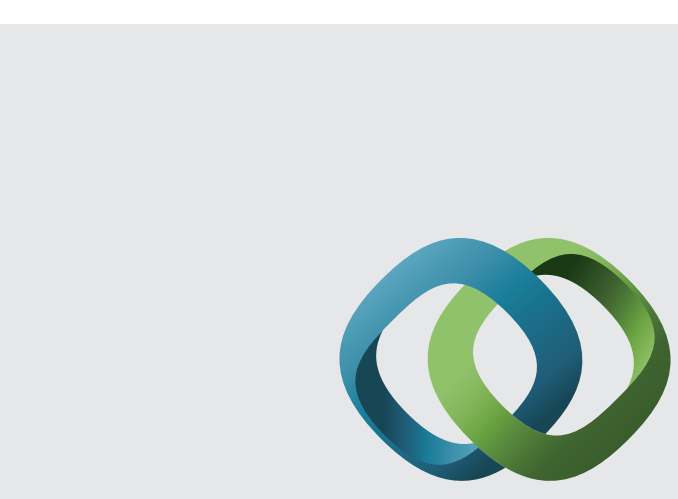

\section{Hindawi}

Submit your manuscripts at

http://www.hindawi.com
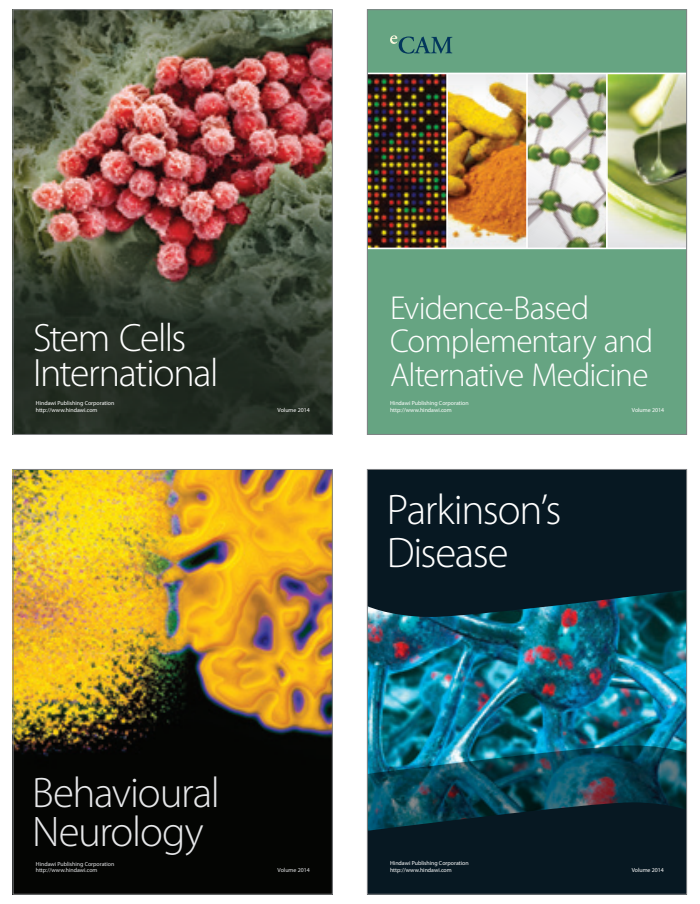
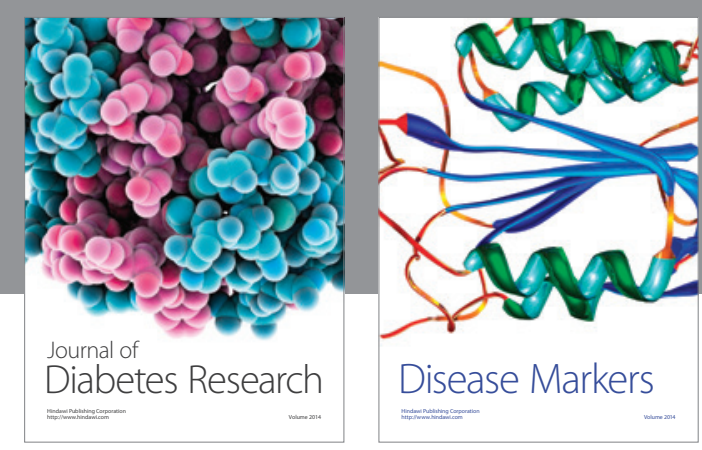

Disease Markers
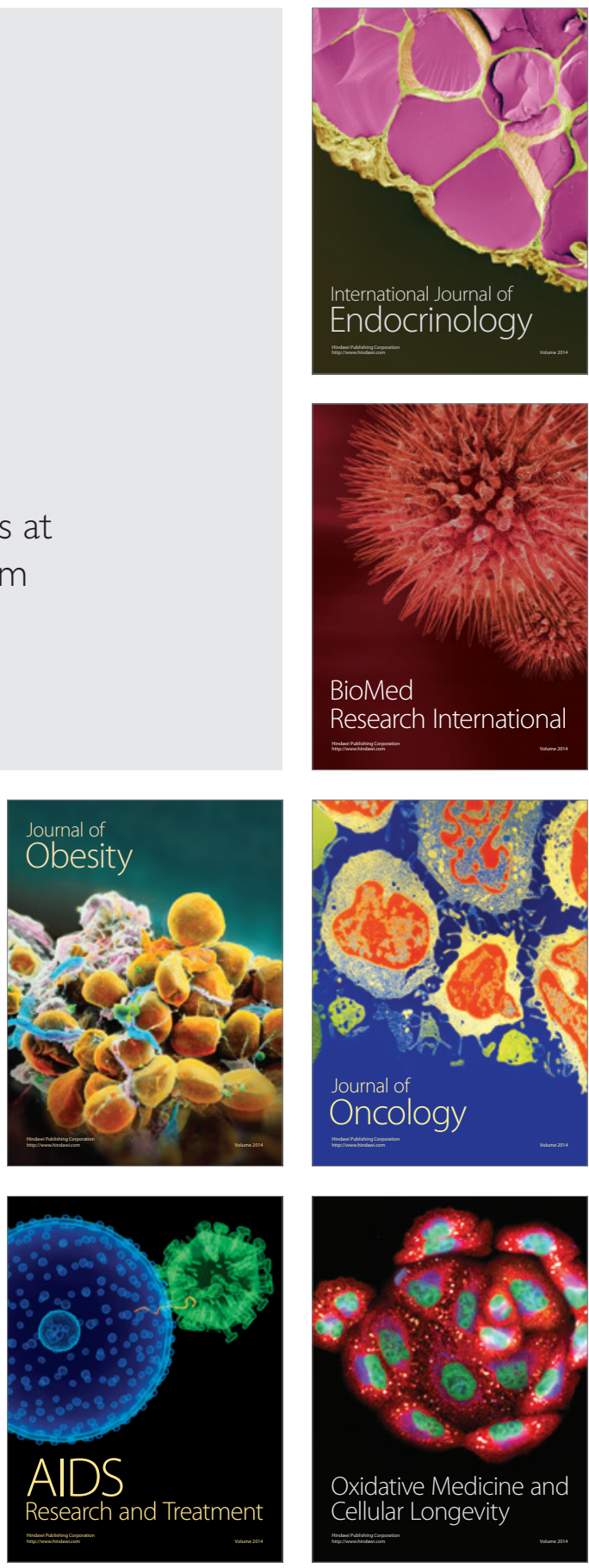